\title{
A comunicação sob o viés da cultura: impactos do pensamento de Martín- Barbero sobre uma tese
}

\section{Lourdes Ana Pereira Silva}

Doutora; Universidade Santo Amaro, São Paulo, SP, Brasil

lourde_silva@hotmail.com

\begin{abstract}
Resumo
Neste artigo (re)visitamos uma tese de doutorado defendida pela autora em 2012. Seu objetivo consiste em evidenciar e problematizar os diálogos estabelecidos entre a referida tese e - pensamento de Jesús Martín-Barbero. A estratégia metodológica para a produção do artigo consistiu em um relato de experiência a partir da releitura da tese e dos principais conceitos barberianos utilizados. Decorridos seis anos desde a produção da tese, é possível inferir que o alcance da obra de Martín-Barbero faz-se presente por meio do seu pensamento epistemológico basilar, qual seja, de reconhecer a comunicação a partir da cultura e de concebê-la como mediadora de todos os aspectos da vida social.
\end{abstract}

\section{Palavras-chave}

Martín-Barbero. Mediações. Identidade. Melodrama.

Epistemologia.

\section{Introdução}

Em novembro de 2017, a Cátedra Jesús Martín-Barbero - Centro Internacional de Estudios Superiores de Comunicación para América Latina (CIESPAL), em parceria com o Programa de Pós-Graduação em Comunicação e Informação da Universidade Federal do Rio Grande do Sul (UFRGS), promoveu, em Porto Alegre (RS), o evento Tributo a MartínBarbero. 0 principal objetivo do encontro era comemorar os 30 anos da publicação da obra Dos meios às mediações. Comunicação, cultura e hegemonia (MARTíN-BARBERO, 1997). Este artigo teve sua origem em uma das mesas daquele evento, intitulada Jesús Martín-Barbero e 
os desdobramentos da pesquisa brasileira, composta por mim, Lourdes Silva, e Valquíria John, Mônica Pieniz e Graziela Bianchi, além da debatedora, Rosário Sanchez.

A interlocução na mesa deu-se a partir da produção da minha tese, de modo que este artigo tem por objetivo evidenciar e problematizar os diálogos estabelecidos naquela pesquisa com o pensamento de Martín-Barbero salientando, inclusive, os processos que me conduziram a uma possível filiação teórica com o autor.

Cabe observar que este artigo é, em alguma medida, um relato de experiência. Relatos de experiências versam sobre uma espécie de investigação cientifica que requer a demonstração de uma experiência prática para maior compreensão e fundamentação de uma teoria. Apesar de considerar que um relato de experiência acadêmico jamais seja um ato solitário, excepcionalmente optei pelo uso da primeira pessoa do singular. Tal relato, coloca-me em diálogo comigo mesma, com outros sujeitos que participaram dessa experiência, bem como com aqueles que o leem. Assim, busquei relatar de modo contextualizado a partir dos aportes teóricos de referência para a esta experiência. Esta proposição dialoga com a relação sujeito-objeto ao considerar as diversas condições de produção de realização da pesquisa em questão, desde as individuais, quanto as coletivas, como por exemplo, àquelas de caráter científico.

Desse modo, a tese Melodrama como matriz cultural no processo de constituição de identidades familiares: um estudo de (tele)novela ${ }^{1}$ e bumba-boi - usos, consumo e recepção, teve como objetivo "Compreender a constituição das identidades familiares por meio das relações vivenciadas com o gênero melodramático, exploradas em suas várias dimensões e manifestações, o que inclui a telenovela, tendo como ponto de partida estudo de uma família modelar." (SILVA, 2012, p. 23).

0 problema de pesquisa consistiu em solucionar "[...] de que modo o gênero melodrama - nas suas atualizações através da (tele)novela, do bumba-boi e das práticas sociocomunicativas de uma família de classe popular - se constitui uma matriz cultural para a identidade familiar?" (SILVA, 2012, p. 23).

À vista disso, trabalhei perspectivas diacrônica e sincrônica de três gerações de uma família almejando identificar os usos, o consumo e a recepção de tele(novela), assim como

\footnotetext{
1 Na tese, o uso dos termos novela e telenovela são utilizados de modo distinto e não como sinônimos. Nomeadamente utilizamos novela para designar um formato que pode ser entendido a partir de diversos meios/formatos e, portanto, remetem a diferentes linguagens, estéticas, modos de produção e recepção/consumo, como por exemplo, a fotonovela, a radionovela. Quanto ao termo telenovela, trata-se da novela vista a partir da televisão. Embora tanto um formato quanto outro tenha sua origem no melodrama, tal distinção não se trata de uma questão meramente semântica, visto ter implicações nas diversas instâncias da pesquisa (teórica, epistemológica, empírica). Na perspectiva teórica a própria historicidade da novela, perpassa paulatinamente diversos formatos como folhetim e radionovela.
} 
outras práticas midiáticas e sociocomunicativas; debati sobre os aspectos históricos e conceituais do melodrama e suas vinculações com a (tele)novela e o bumba-boi; dissertei a partir de distintas matrizes culturais do melodrama articuladas à produção e difundidas por esses dois formatos narrativos; ponderei, a partir de distintas áreas do conhecimento, a noção de identidade.

No que concerne à questão metodológica, delineei um referencial que contemplou tanto a reflexão teórica quanto a pesquisa metódica, de modo a optar pelo método da história oral a partir da técnica "história de família". A partir desse método, elegi entrevistas do tipo semiestruturada e em profundidade, além do questionário e de observações etnográficas.

Quanto aos resultados, destaquei que a família possuía um repertório simbólico compartilhado, que se reconhece e se percebe também nos discursos midiáticos - de modo especial naqueles de matriz melodramática, entretanto, dispunha de outros saberes e de outras referências culturais não midiáticas para pensar e construir suas percepções de mundo e constituírem-se continuamente, desde diferentes gerações e a partir de identidades familiares.

Tais identidades, conceitualmente, caracterizam-se, sobretudo, pelo sentimento de pertencimento quer à própria linhagem, quer à cidade ou ao bairro em que vivenciavam sua sociabilidade; e também pela forte relação entre a fé e o lúdico vivenciados nos modos de expressarem sua religiosidade e festividades. A investigação corroborou que as diversas aplicações do estudo dessa família permitem levantar hipóteses sobre outros fenômenos similares. A (tele)novela, como parte da cultura midiática, traz em si as marcas da contemporaneidade.

\section{0 processo de filiação teórica, ou, sobre como cheguei em Martín- Barbero}

Ao repensar o caminho percorrido nos modos de produção da tese, sinto que não posso ignorar meu lugar de fala e daquilo que experienciei. Alinho-me ao posicionamento de diversos autores (MILLS, 1982; MARTÍN-BARBERO, 2004; FLICK, 2009) sobre as indissociabilidades pessoal e intelectual do pesquisador que observa que a constituição do objeto dá-se antes mesmo da pesquisa. 
Wright Mills (1982) afirma que pesquisadores não separam a pesquisa que realizam das suas vidas, uma vez que considera que há um processo de entrelaçamento entre o pessoal e o intelectual. Para o autor, não existe o iniciar exato da pesquisa, visto que sua gênese está na experiência de vida do pesquisador, o que, consequentemente, motiva-o e coloca-o em vigilância com sua produção.

Nesse complexo processo de (re)construção do conhecimento, Mills (1982) adverte para a importância do arquivo do pesquisador acerca de temáticas inicialmente estimuladas pelo método empírico, arquivo este que aguça a curiosidade epistemológica. Assim, a filiação teórica pode ser considerada como a anuência dada pelo pesquisador a uma determinada perspectiva teórica.

Considero relevante refletir de onde parto para construir este relato, por entender que isso contribui para compreensão da eleição dos recortes acionados pela memória, uma vez que o pesquisador não investiga algo fora de si, pois o objeto está constituído antes mesmo da pesquisa. Faço adesão ao pensamento de Flick (2009), quando afirma que as questões de pesquisa originam-se na biografia pessoal do pesquisador e em contato com seu contexto social. Essas marcas que o pesquisador carrega consigo certamente contribuem à apreensão que ele faz da realidade, bem como o engajamento teórico e o compromisso social que tem para com a pesquisa. Em Ofício do cartógrafo. Travessias latino-americanas da comunicação na cultura, Martín-Barbero (2004, p. 25) resgata um pensamento de Gramsci, que pondera que "[...] só investigamos de verdade o que nos afeta." Cabe ressaltar que, a raiz da palavra afetar vem de afeto.

Esses pressupostos remetem à ideia de que as questões de pesquisa originam-se na biografia do pesquisador e na sua relação com seu contexto social. Deste modo, meus primeiros contatos com o pensamento de Martín-Barbero, ou o que pode ser entendido como o início de um processo de filiação teórica barberiana, ocorreu em 2002, durante um curso de Pós-Graduação Lato Sensu Teórico-Prático em Comunicação Social promovido pela Universidade São Francisco², a partir de aulas ministradas pela professora Sílvia Borelli. Decorridos 15 anos, lembro-me ainda do entusiasmo da professora ao falar da obra Dos meios às mediações: comunicação, cultura e hegemonia (MARTÍN-BARBERO, 1997), e da novidade de o livro causar embaralhamento nas bibliotecárias ao catalogá-lo, visto que a obra percorre diversas disciplinas, desafiando-as a eleger uma. 0 caráter interdisciplinar

\footnotetext{
${ }^{2}$ Em parceria com o SEPAC (Serviço à Pastoral da Comunicação).
} 
expresso na obra, bem como o tensionamento epistemológico contido no título, foi fundamental para me causar estranhamento e contentamento.

Foi desse modo que, em 2005, quando da ocasião da elaboração do projeto de pesquisa para a seleção do mestrado, Martín-Barbero tornou-se a principal referência para a investigação que originou a dissertação Páginas da vida, a família brasileira sob a ótica da recepção da telenovela (SILVA, 2008).

Nessa trajetória, destaco duas de suas obras: Dos meios às mediações (MARTÍNBARBERO, 1997) e Televisión y melodrama. Géneros y lecturas de la telenovela en Colombia (MARTÍN-BARBERO; MUÑOZ, 1992). Na primeira obra, destaca-se o aparato conceitual que identifica na cultura de massa a presença do melodrama. $O$ autor assegura que o melodrama é o gênero televisivo de maior expressão na América Latina, o mais aberto às formas de viver e sentir da população. É desse modo que Martín-Barbero vai tecendo seu pensamento ao demonstrar, a partir da memória e do imaginário coletivo, as formas de reconhecimento das culturas populares. Em Televisión y melodrama, Martín-Barbero e Sonia Muñoz (1992) analisam as transformações do gênero e estudam empiricamente os usos sociais da televisão a partir da família no contexto colombiano.

Também em 2005, tomei conhecimento da obra Vivendo com a telenovela. Mediações, recepção e teleficcionalidades (LOPES; BORELLI; RESENDE, 2002). A obra possibilitou maior compreensão da proposição de Martín-Barbero formulada em Dos meios às mediações (MARTÍN-BARBERO, 1997), visto que faz uma aplicação metodológica da teoria das mediações em uma pesquisa de recepção de telenovela e dá ênfase à perspectiva transdisciplinar da comunicação.

Ainda nesse âmbito - na busca por textos basilares para desenvolver a dissertação na perspectiva teórica das mediações -, e já inserida em um programa de mestrado, tomei conhecimento de duas teses: Querência: estudo da audiência e da identidade cultural gaúcha como mediação simbólica (JACKS, 1993) e Identidade étnica, cotidiano rural e telenovela (BONIN, 2001)33, ambas defendidas na Escola de Comunicações e Artes (ECA) da Universidade de São Paulo (USP) e tributárias do pensamento de Martín-Barbero.

0 pensamento de Martín-Barbero esteve presente praticamente em todo percurso do mestrado e do doutorado, fosse nas discussões em sala de aula, nos grupos de pesquisa,

\footnotetext{
3 Na perspectiva de conceber a pesquisa e filiação teórica como um empreendimento coletivo, faz-se necessário informar que o meu projeto de pesquisa integrava a mesma linha de pesquisa da Profa. Dra. Jiani Bonin, no Programa de Pós-Graduação em Comunicação da Unisinos. 0 meu contato com a referida professora também se deu a partir da realização do estágio docente na disciplina Mídia e Cultura.
} 
em produções de artigos e ou nas orientações ${ }^{4}$. 0 processo de formação que vivenciei durante a pós-graduação deu-se no contexto do Rio Grande do Sul, Estado que pode ser considerado, nas últimas décadas, uma espécie de polo dos estudos culturais e de recepção latino-americanos em comunicação no Brasil. Os processos de aprendizagens no âmbito da pós-graduação me fizeram reconhecer a relevância do papel não somente das instituições de ensino em relação à Universidade do Vale do Rio dos Sinos (Unisinos) e à Universidade Federal do Rio Grande do Sul (UFRGS), como também das orientadoras que tive nesse processo. Leia-se as professoras Denise Cogo e Nilda Jacks, ambas tributárias do pensamento de Martín-Barbero, seja por meio das produções de suas pesquisas, seja por meio de dezenas de orientações articuladas a esse pensamento no exercício da docência.

Do igual modo, identifico não somente o autor Martín-Barbero, mas também a interferência da Universidade de São Paulo (USP) na trajetória daquelas que foram minhas orientadoras. Percebo-me inserida em um contexto social que contribuiu para o que estou denominando nesta ação de revisitar a tese na perspectiva de minha filiação teórica do pensador.

Desse modo, destaco a dimensão coletiva do conhecimento ou, nos moldes de Bertaux, para quem "[...] a pesquisa é um empreendimento coletivo e, em princípio, cumulativo, para o qual cada pesquisa traz sua própria contribuição." (BERTAUX, 2010, p. 26). Nos enunciados que seguem, é possível observar, a autorreflexão feita por duas pesquisadoras sobre suas trajetórias acadêmicas no campo da comunicação.

A formação de mestrado me possibilita o encontro com os estudos culturais latino-americanos e com a perspectiva dos estudos de recepção já durante o meu primeiro ano como estudante de pós-graduação da ECAUSP. Leio e debato textos de pesquisadores latino-americanos como Jesús Martín-Barbero e Néstor García Canclini, introduzidos como bibliografia de um seminário sobre estudos comunicacionais latino-americanos. [...] No final do mesmo ano (1991), o reencontro com um esses autores - MartínBarbero - dessa vez, presencialmente, na condição de integrante da plateia do seminário sobre estudos de recepção na América Latina ${ }^{5}$, me possibilita perceber novas intersecções entre o pensamento latino-americano e as experiências e práticas de comunicação alternativa e popular dos movimentos sociais relacionadas aos processos de cidadania e às lutas pela democratização dos meios de comunicação das sociedades latinoamericanas. [...] Vislumbro nesses primeiros encontros acadêmicos do

\footnotetext{
4 A propósito, o termo orientação significa ação ou efeito de orientar, o que pressupõe uma relação pedagógica que se estabelece entre orientando e orientador. Assim, depreendo que o processo de construção do conhecimento não é uma atividade isolada e necessita da interação entre os sujeitos orientador e orientando.

5 O seminário foi promovido pelo grupo de pesquisa coordenado por Mauro Wilton de Sousa, professor e pesquisador da Escola de Comunicação e Artes da Universidade de São Paulo, dando origem, posteriormente, a uma das primeiras obras de referência dos estudos de recepção no Brasil:, Sujeito, o lado oculto do receptor (SOUSA, 1994).
} 
mestrado as potencialidades científicas e políticas de articulação entre a comunicação popular e alternativa refletida no pensamento de intelectuais latino-americanos como Maria Cristina Mata, Rosa Alfaro, Paulo Freire, Mario Kaplún e Luis Ramiro Beltrán, com a epistemologia da comunicação e da cultura de Martín-Barbero. (COGO, 2013, p. 4, grifo nosso).

A pesquisadora, além de evidenciar o início de uma filiação teórica, evidencia também uma formação com princípios de discernimento político, social e, sobretudo, nas questões referentes à América Latina. Tais posicionamentos também encontram-se presentes no pensamento de Martín-Barbero.

No trecho a seguir, Jacks (2015) relata sua trajetória no âmbito profissional, considerando as contribuições do pensamento latino-americano no campo da comunicação. Entre outros autores, destaca seu tutor no estágio pós-doutoral, Martín-Barbero.

Na Pós-Graduação as disciplinas foram adequando-se às mudanças nas linhas de pesquisa, mas sempre giraram em torno das relações entre comunicação e cultura, estudos de recepção comunicação e identidade cultural, especialmente a regional, e mais recentemente técnicas de pesquisa qualitativa. A pesquisa aconteceu sob um influxo muito importante iniciado nos anos 1980, patrocinado pela renovação teórica que se deu nos principais países da região com apoio e atuação das mais importantes instituições de pesquisa e pesquisadores da área. Elas fizeram circular o debate que se desenvolvia em contraposição às teorias hegemônicas herdadas da tradição europeia e norte-americana, cujas lideranças podem ser identificadas em nomes como Jesús Martín-Barbero, Néstor García Canclini, Maria Cristina Mata, Jorge González, entre outros, os quais foram antecedidos pelos "pais fundadores": Antonio Pasqualli, Armand Mattelart, Luis Ramiro Beltrán, Eliseo Verón e Paulo Freire. (JACKS, 2015, p. 11, grifos nossos).

A pesquisadora ressalta o abandono de uma teoria, ou melhor, refere-se a uma "renovação teórica", àquela que se interessa, nos moldes de Gramsci, pela hegemonia, pelos conflitos, que articula a cultura, para então conceber que, o problema subjacente não se localiza mais nos meios de comunicação, mas nos mediadores e nos modelos culturais (MARTÍN-BARBERO, 1997).

Reconheço nestas profissionais dois perfis de professoras pesquisadoras, apaixonadas pelo universo da pesquisa, em especial pela pesquisa empírica, atentas aos meandros e às exigências das questões metodológicas, ao sentimento de pertencimento latino-americano expresso em suas trajetórias de pesquisas. Sentimentos e posicionamentos com os quais não somente me identifico, mas que também reforçaram em mim o desejo e a 
necessidade de produzir ciência considerando as estruturas globais, sem ocultar ou desconsiderar a referência do continente em que vivo, ou seja, de problematizar o "lugar" como possibilidade de conhecimento da realidade.

Neste sentido, a eleição de uma cidade maranhense como lócus de pesquisa no mestrado e no doutorado, mesmo ao considerar a dificuldade que tive de operacionalizar a logística da investigação, constituiu-se um posicionamento consciencioso e político, de almejar produzir conhecimento sobre um Estado carente de investigação. Como bem assinala Martín-Barbero em proposição para uma agenda nacional, trata-se não somente de questão teórico-metodológica, mas de questão ética e política, sobre para quem e para quê pesquisamos (MARTÍN-BARBERO, 2011).

\section{Excertos barberianos}

Neste tópico, buscarei especificar as características da apropriação feita do pensamento de Martín-Barbero, mediante a análise da tese na qual há referências e incorporações de conceitos e/ou assimilação de seu pensamento.

Considerando que a cultura popular e suas expressões mediante o melodrama é um dos eixos de trabalho do autor, apropriei-me sistematicamente de noções e conceitos, tais como matrizes culturais, identidade, gênero, resíduos, espaço social etc. Metodologicamente, a tese não se utiliza ou aplica o mapa das mediações, ainda que a concepção epistemológica do autor tenha permeado praticamente toda a produção da pesquisa. Busquei tensionar a preocupação central da pesquisa com o modus operandi da teoria, quando se tratou da construção do objeto, da análise reflexiva, do pensar relacional, de modo interdisciplinar etc.

Ao considerar que a história da comunicação não começa com os meios massivos, mas muito antes, a partir de outras formas culturais, a comunicação passa a recuperar esses espaços em que a palavra torna-se ação por meio de distintas narrativas, da profecia, da poesia, dos trovadores, do mito etc., formas estas consideradas como figuras arcaicas. Assim, apresentamos na figura abaixo, o que se considerou um dos principais achados da tese. 
Figura 1 - Formas culturais (narrativas ficcionais e melodramáticas)

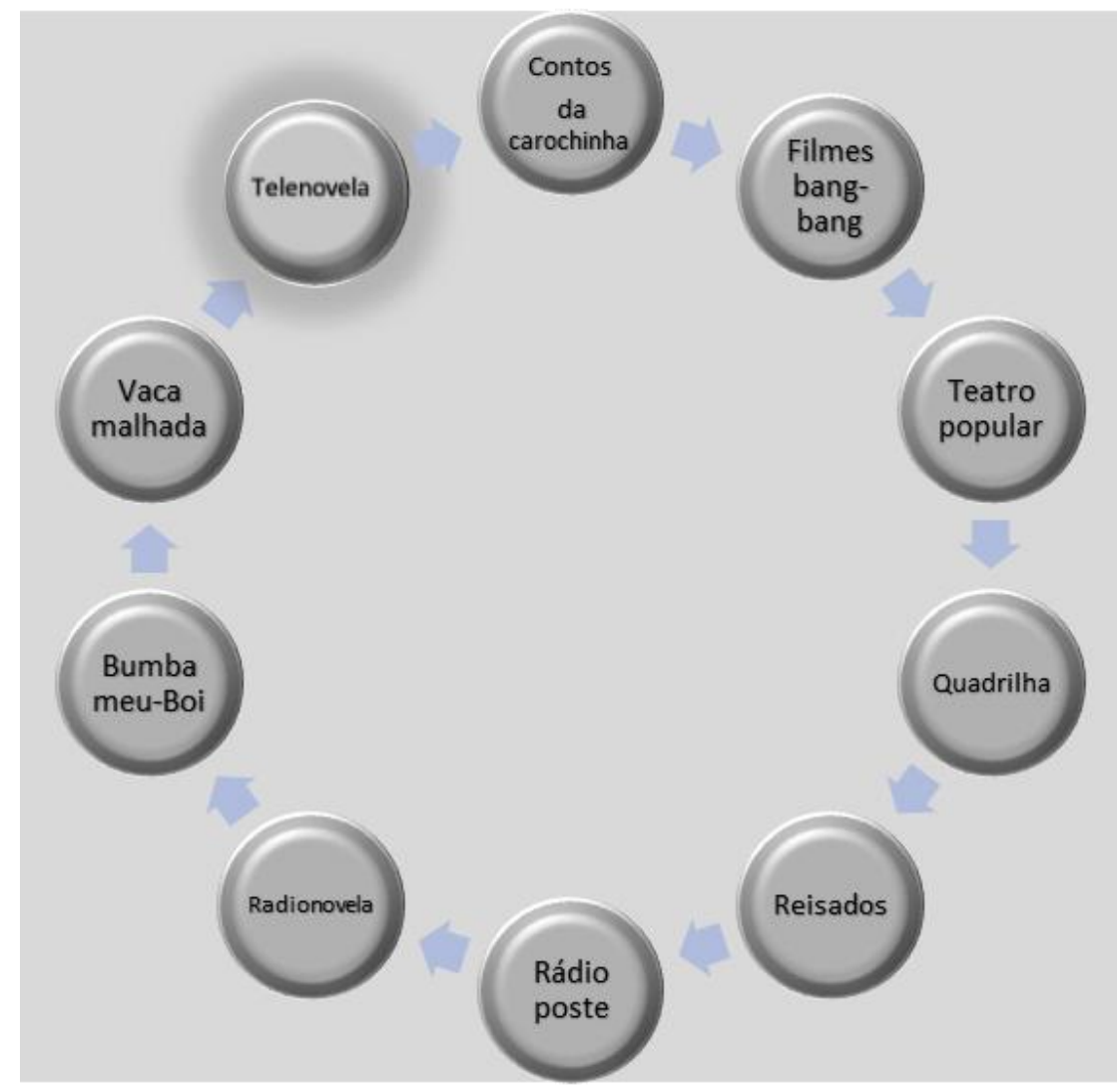

Fonte: Adaptado de Silva (2012).

As formas culturais apresentadas na figura anterior foram identificadas na história da família estudada e problematizadas sistematicamente nas instâncias analítica e interpretativa da tese. Tais formas dialogam diretamente com as ideias-força da cotidianidade familiar identificadas, como: autoestima e processos de pertencimento; questão étnico-racial; a moradia, a vivência no bairro e na cidade; as relações consanguíneas como fator de sociabilidade; a relação entre trabalho e classe; e a religiosidade familiar e a dimensão festiva da família.

Cabe ressaltar que, inicialmente, a investigação focou na recepção de telenovela, entretanto, no decorrer da pesquisa, foi se tornando evidente que a cultura da novela na história de família antecedia à cultura da (tele)novela. As entrevistas e as demais técnicas de pesquisa possibilitaram verificar a profunda relação entre a família e os processos comunicacionais e midiáticos vivenciados, em especial no que se refere à relação com a matriz do melodrama. 
As práticas midiáticas estiveram presentes na família desde a primeira geração. A mídia provocou grandes impactos na vida do grupo familiar, de modo a revelar que, a novela enquanto tradição popular e melodramática antecede à telenovela, isto é, a novela vista na televisão. Desse modo, a Figura 1 evidencia outros modos de a família conviver com a novela e também com outros formatos midiáticos e socioculturais que têm por gênero o melodrama. A trajetória familiar demonstra o contato com narrativas ficcionais e melodramáticas, a exemplo de práticas vivenciadas como os contos da carochinha, das rodas de histórias, do consumo dos filmes e da literatura de bangue-bangue, das peças de teatro popular ensaiadas e encenadas, do consumo da radionovela e do bumba-boi.

A (tele)novela é uma narrativa cultural que se manifesta não somente através das suas tramas, mas também como manifestação simbólica que, ao ser contada, o sujeito (e grupos) fala(m) de si mesmo(s), reconhece(m)-se e identifica(m)-se nos valores expressos pelos personagens em uma espécie de identidade cultural. Ao repercutir na vida social e cotidiana, o melodrama se constitui em um objeto crucial na construção da identidade familiar. É por essa via que esse gênero extrapola a mera noção de ser apenas um gênero para configurarse como uma visão de mundo (SILVA, 2012).

Os modos de interação que resultaram a partir dessas e nessas formas culturais nos fizeram aderir à proposição que "[...] a verdadeira proposta do processo de comunicação e do meio não está nas mensagens, mas nos modos de interação que o próprio meio transmite ao receptor." (MARTÍN-BARBERO, 2003, p. 55). A história da família, permeada pelo contexto midiático e pelas práticas sociocomunicativas, não foi concebida como estática ou minimizada a dados apenas conjunturais, mas verificada a partir das transformações que ocorreram gradualmente em uma perspectiva diacrônica, enquanto fenômeno dinâmico, isto é, a partir de uma perspectiva histórica.

\section{Considerações finais}

O objetivo deste artigo foi evidenciar e problematizar os diálogos estabelecidos entre a referida tese e o pensamento de Martín-Barbero. Assim, salientei o processo de filiação teórica com o referido autor, fundamentando as opções epistemológicas da tese; enfatizei a compreensão da pesquisa como um empreendimento coletivo; e destaquei o diálogo estabelecido com o pensamento barberiano a partir dos principais conceitos tensionados na investigação. 
Na língua portuguesa, relatar fatos relaciona-se diretamente a memórias. E por memória, a faculdade de reter ideias, impressões e conhecimentos adquiridos anteriormente. Assim, revistar a tese a partir do seu autor basilar vai além da narração de fatos, implica sistematização e, de alguma forma, perceber como a história vai se constituindo como resultado das inquietações que nascem no limite da dialética entre teoria-prática.

Redigir um relato dessa natureza demanda reflexividade, o que possibilitou identificar em minha trajetória acadêmico-profissional a conexão com algumas temáticas. Tenho feito um percurso que também se encontra articulado às minhas áreas de interesse e que evidenciam aderências temáticas e curriculares. Observo, por exemplo, as pesquisas desenvolvidas no âmbito dos estudos de recepção de ficção televisiva que se iniciam por ocasião do mestrado, têm continuidade na produção da tese e têm se desenvolvido na participação das pesquisas do Observatório de Ficção Televisiva (Obitel) ${ }^{6}$.

o pensamento de Martín-Barbero foi fundamental para que eu saísse da lógica usual de fazer estudo de recepção a partir de um produto específico e buscasse compreender as questões mais profundas, basilares e de matriz, como àquelas de gênero e formatos que sugerem ampliar a perspectiva de observar o objeto, bem como as questões das instâncias teórica, metodológica, técnica e epistemológica.

Nesse sentido, refletir desde uma perspectiva interdisciplinar, transitando, por exemplo, por questões da cultura comunicativa, me possibilitaram compreender que, apesar de as ciências da comunicação se preocuparem em buscar especificidades a partir de objetos restritos à dimensão humana e midiatizados por suportes técnicos, ou seja, como os sujeitos se encontram implicados nesses objetos, não me impediram de recrudescer no fechamento do objeto da comunicação na mídia, excluindo diversas práticas comunicativas (de produção - veiculação, circulação-contexto e de consumo-público).

0 que me pareceu ideal foi identificar que, o que estava em jogo na localização desse objeto não se restringia ao suporte no qual ele se expressava, mas qual o sentido de troca que se estabeleceu a partir da percepção recíproca do outro. Ao que tudo indica, foi exatamente o redimensionamento do objeto que abriu possibilidades metodológicas e implicou na concepção constante de novos métodos e na revisão de procedimentos e técnicas na produção da tese.

\footnotetext{
${ }^{6} 0$ Obitel Brasil é uma Rede Brasileira de Pesquisadores da Ficção Televisiva constituída em 2007. 0 observatório reúne as equipes de pesquisadores brasileiros oriundos de diversas universidades brasileiras que se dedicam ao estudo da ficção televisiva.
} 


\section{Referências}

BERTAUX, Daniel. Narrativas de vida. A pesquisa e seus métodos. São Paulo: Paulus, 2010.

BONIN, Jiani Adriana. Identidade étnica e telenovela. 2001. Tese (Doutorado em Ciências da Comunicação) - Universidade de São Paulo, São Paulo, 2001.

COGO, Denise. Memória da trajetória e produção acadêmica. Porto Alegre, 2013. No prelo. Memorial da autora.

FLICK, Uwe. Introdução à pesquisa qualitativa. 3. ed. Porto Alegre: Artmed, 2009.

JACKS, Nilda. A recepção na querência: um estudo da audiência e da identidade cultural gaúcha como mediação simbólica. 1993. Tese (Doutorado em Ciências da Comunicação) Escola de Comunicações e Artes, Universidade de São Paulo, São Paulo, 1993.

JACKS, Nilda. Pequeno relato de um projeto acadêmico (1982-2015): memorial para progressão a professor titular. Porto Alegre, 2015. No prelo. Memorial da autora.

LOPES, Maria Immacolata Vassallo; BORELLI, Silvia Helena Simões; RESENDE, Vera da Rocha. Vivendo com a telenovela: mediações, recepção e teleficcionalidade. São Paulo: Summus, 2002.

MARTÍN-BARBERO, Jesús. Dos meios às mediações: comunicação, cultura e hegemonia. Rio de Janeiro: Ed.UFRJ, 1997.

MARTÍN-BARBERO, Jesús. Dos meios às mediações: comunicação, cultura e hegemonia. 2. ed. Rio de Janeiro: Ed. UFRJ, 2003.

MARTÍN-BARBERO, Jesús. Ofício de cartógrafo. Travessias latino-americanas da comunicação na cultura. São Paulo: Loyola, 2004.

MARTÍN-BARBERO, Jesús. Reubicando el campo de las audiencias em el descampado de la mitación cultural. In: JACKS, Nilda et al. (Org.). Análisis de recepción en América Latina: un recuento histórico con perspectivas al futuro. Quito: Editorial Quipus, CIESPAL, 2011. p. 451-461.

MARTÍN-BARBERO, Jesús; MUÑOZ, Sonia. Televisión y melodrama. Géneros y lecturas de la telenovela en Colombia. Bogotá: Tercer Mundo Editores, 1992. 299 p.

MILLS, Charles Wright. A Imaginação Sociológica. Rio de Janeiro. Zahar, 1982.

SILVA, Lourdes Ana Pereira. Páginas da Vida, a família brasileira sob a ótica da recepção da telenovela. 2008. Dissertação (Mestrado em Ciências da Comunicação) - Universidade do Vale do Rio dos Sinos, São Leopoldo, 2008. 
SILVA, Lourdes Ana Pereira. Melodrama como matriz cultural no processo de constituição de identidades familiares: um estudo de (tele)novela e bumba meu boi usos, consumo e recepção. 2012. Tese (Doutorado em Comunicação e Informação) Universidade Federal do Rio Grande do Sul, Porto Alegre, 2012.

SOUSA, Mauro Wilton (Org.). Sujeito, o lado oculto do receptor. São Paulo, Brasiliense, 1994.

\title{
Communication under the bias of culture: impacts of Martín-Barbero's thinking on a thesis
}

\begin{abstract}
The article (re)visits a doctoral thesis defended by the author in 2012. The objective is to highlight and problematize the dialogues established with the thought of Jesus Martín-Barbero. The methodological strategy for the production of the article consisted in re-reading the thesis and Martín-Barbero's main concepts. After six years since the production of the thesis, it is possible to infer that the reach of Martín-Barbero's work is present through his basic epistemological thought, that is, of recognizing communication from the cultural, of conceiving it as mediator of all aspects of social life.
\end{abstract}

\section{Keywords}

Martín-Barbero. Mediations. Identity. Melodrama. Epistemology.

Recebido em 16/03/2018

Aceito em 13/05/2018 